ISSN : 2087-2461

PENANGGUNG JAWAB

Dekan FIKOM

Evie Sofiati MI, M.I.Kom

Sekretaris Dekan

Dian Marhaeni K, M.Si

Ketua Penyunting

Made Dwi Adnjani, M.Si

Sekretaris

Mubarok, M.Si

Bendahara

Parwati, SH

Dewan Penyunting

Trimanah, M.Si

Edi Ismoyo, M.Si

Suharyoso, S.Sos

Seksi Usaha

Endang Winarsih, S.Sos

Sirkulasi dan Distribusi

Novi, S.Sos

Alamat Redaksi

Fakultas Ilmu Komunikasi

Universitas Islam

Sultan Agung Semarang

Jl. Raya Kaligawe Km. 4

Po. Box 1054/SM

Semarang 50112

Telp. (024) 6583584

ext. $448 / 449$

Fax. (024) 6582455

email : jurnalfikom@yahoo.com
Pergeseran Makna Motif Batik Yogyakarta - Surakarta

Doddy Wihardi

Email:made_doddywihardi@yahoo.com

Riyodina G.Pratikto

Email:dinapratikto@yahoo.com

Shinta Kristanty

Email:shintasoultan@yahoo.com

Diskursus Cyberbullying Florence Sihombing

(Analisis Wacana Kritis Teun A. Van Dijk

Tentang Florence Sihombing di Dunia Maya)

Syntia Balina Dewi

syntiabalinadewi@gmail.com

Syarif Maulana

syarafmaulini@gmail.com

Kajian Interaksi Simbolik Pola Komunikasi

Etnis Arab dan Etnis Sunda Dalam Perkawinan Mut'ah

di Kecamatan Pacet Kabupaten Cianjur

Yessi Sri Utami

yessikhansa@gmail.com

Tabloidisasi Pemberitaan Mengenai Pemilu Presiden 2014

Pada Program Berita "Headline News" Metro TV

Urip Mulyadi

oeripmulia@gmail.com

Relevansi Teori Agenda Setting

Dalam Dunia Tanpa Batas

Kharisma Nasionalita

k_nasionalita@yahoo.co.id

"Children Go Online" di Indonesia, Apa dan Bagaimana? Nurist Surayya

nurist.surayya@undip.ac.id 


\title{
RELEVANSI TEORI AGENDA SETTING DALAM DUNIA TANPA BATAS ${ }^{1}$
}

\author{
Kharisma Nasionalita \\ Telkom University, Bandung \\ k_nasionalita@yahoo.co.id
}

\begin{abstract}
Abstrak
Teknologi mengubah landscape media secara kontinyu beralih basis online dimana pesan atau informasi didiseminasikan secara instan. Semua menjadi terbuka dan tidak tidak terbatas, maka informasi menjadi lebih bebas, menciptakan The Borderless World. Beberapa media massa mulai berkurang audiensnya. Surat kabar cetak mengalihkan usahanya dalam bentuk media online newspaper ataupun newsportal. Teknologi membawa perubahan yang simultan, media berubah lebih personal. Media online mudah diakses dan tersedia dalam berbagai kanal, namun membuat audiens terfragmentasi dengan suplai informasi meningkat. Pembentukan agenda media dan agenda publik kemudian berubah, memunculkan sebuah pertanyaan mengenai relevansi agenda setting dikaitkan dengan transformasi teknologi dan perubahan di masyarakat yang semakin dinamis.
\end{abstract}

Keywords: Agenda setting, media online, media agenda, public agenda

\begin{abstract}
Technology is continuously changing media landscape turn into online, where the message or information disseminated instantly. All to be open and not restricted, then the information becomes more freely, this situation creates The Borderless World. Some mass media audiences began to diminish. Print newspapers divert their business to media newspaper or news portal. Technology brings changes simultaneously, and media become more personal. Online media are easily accessible and available in a variety of channels, but make the audience fragmented by increasing the supply of information. Formation of the media agenda and the public agenda change, which raises a question about relevancy of agenda setting that being associated with the transformation of technology and changes in society which is increasingly dynamic
\end{abstract}

Keywords: Agenda setting, media online, media agenda, public agenda

\section{Pendahuluan}

Teori Agenda Setting menciptakan salah satu teori yang cukup populer dikalangan peneliti media guna mendedah apa yang dilakukan media terhadap khalayak. Agenda Setting menempatkan besarnya pengaruh media massa dalam mempengaruhi khalayak mengenai prioritas kepentingan sebuah isu. Media disebutkan mampu mengarahkan isu dalam masyarakat dan mampu membuat agenda dimana isu diramu untuk menjadi sebuah diskursus di masyarakat. Agenda Setting merupakan teori komunikasi massa yang pertama kali diuji secara empirik oleh Maxwell Combs dan Donald L Shaw di tahun 1968 pada pemilihan presiden Amerika Serikat. Mereka menemukan bahwa prioritas isu kampanye dalam media massa dianggap khalayak sebagai isu-isu yang penting.

Ide pokok teori Agenda Setting adalah media memberi atensi yang berbeda pada setiap isu atau peristiwa. Apa yang dianggap penting bagi media menjadi penting dimata khalayak. Media memiliki kekuatan menentukan porsi atensi pada suatu isu atau peristiwa dan menyematkannya dalam benak publik. Isu dan peristiwa tersebut hadir ke tangan publik melalui saluran informasi (Channel) seperti media massa. Lalu, bagaimana jika channel itu berubah? 
Saluran informasi (Channel) berubah seiring hadirnya Internet. Penggunaan Internet meningkat dari tahun ke tahun secara signifikan, disebutkan dalam data Internet
World States bahwa ada lonjakan User yang signifikan dari tahun 2010-2012 seperti pada table berikut ini :

Tabel 1.

Internet Usage and Population Statistics, 2000, 2007-2010 and 2012

\begin{tabular}{|c|c|c|c|}
\hline Year & User (millions) & Population (millions) & User as \% of total population \\
\hline 2000 & 20 & 206,27 & 9,7 \\
\hline 2007 & 20 & 224,48 & 8,9 \\
\hline 2008 & 25 & 237,51 & 10,5 \\
\hline 2009 & 30 & 240,27 & 12,5 \\
\hline 2010 & 30 & 243,0 & 12,3 \\
\hline 2012 & 55 & 248,01 & 22,1 \\
\hline
\end{tabular}

(Sumber : Internet World States 2012)

Kehadiran Internet kemudian newspaper merupakan Koran atau surat kabar mengubah platform media. Di Indonesia, yang berada di world wide web atau Internet, media online mulai dilirik sebagai referensi yang merupakan bagian terpisah atau versi Informasi. Indikasinya, ada kenaikan jumlah online dari surat kabar yang hadir dicetak konsumen media massa yang beralih ke media secara periodikal. Karakter media online online. Dari tercatat antara tahun 2007-2009 makin banyak pembaca Koran dan pendengar radio di Indonesia going online. Sejak 2005, jumlah print reader untuk Koran, majalah, dan tabloid menurun dari tahun ke tahun (www. viva.co.id)

Gejala turunnya print reader juga didorong oleh munculnya portal-portal berita atau online newspaper di Indonesia. Online Newspaper, dikenal juga sebagai web newpaper adalah interaktif,menyertakan unsur-unsur multimedia dan bersifat real time. (Althaus dan Tweksburry, 2002 : 180-207). Kemudian dari data Biro Pusat Statistik (BPS) 2010 dalam Country Report Mapping Digital Media in Indonesia (2013:17) memperlihatkan hal yang sama. print reader menurun dari tahun ketahun, Penggunaan Intenet dan televisi meningkat dari tahun ketahun.

Tabel 2.

Population (Above 10 years old) accessing radio, television, newspaper, magazines, and Internet (\%), 2003, 2006, 2009 dan 2010

\begin{tabular}{|l|l|l|l|l|}
\hline Media & 2003 & 2006 & 2009 & 2010 \\
\hline Radio & 50,2 & 40,2 & 23,5 & $\mathrm{n} / \mathrm{a}$ \\
\hline Televison & 84,9 & 85,5 & 90,2 & $\mathrm{n} / \mathrm{a}$ \\
\hline Newpaper/Magazine & 23,7 & 23,4 & 18,9 & $\mathrm{n} / \mathrm{a}$ \\
\hline Internet & $\mathrm{n} / \mathrm{a}$ & $\mathrm{n} / \mathrm{a}$ & $\mathrm{n} / \mathrm{a}$ & $\mathrm{n} / \mathrm{a}$ \\
\hline
\end{tabular}

Sumber : Country Report Mapping Digital Media in Indonesia 2013

Pada perkembangannya, teknologi mengubah media secara kontinyu beralih pada basis online dimana pesan atau informasi didiseminasikan secara instan. Media Online yang interaktif meningkatkan keaktifan penggunannya, menjadikan media ini lebih bersifat personal. mudah diakses dan tersedia dalam banyak kanal. Kehadirannya membuat audiens terfragmentasi dan suplai informasi meningkat. Berangkat dari hal ini, W. Lance Bennet dan Shanto Iyegar melontarkan bahwa ini merupakan "New Era of Minimal Effect?". Mereka mempertanyakan efek agenda setting media Online pada publik dikaitkan dengan 
transformasi dan perubahan di masyarakat yang semakin dinamis (Bennet dan Iyegar, 2008:2). Kemudian timbul agenda setting ini masih relevan diaplikasikan pada komunikasi online. Apakah media online mampu mengarahkan isu pada public yang yang dinamis mengingat karakter media online dan media massa sangat berbeda.

Tulisan ini bertujuan menjelaskan secara lebih lanjut mengenai peluang-peluang apakah teori agenda setting masih relevan di terapkan pada komunikasi pada media online,. Tentu saja, tidak sekedar berangkat dari asumsi-asumsi semata, perlu dilakukan pengujian secara empiris melalui sebuah penelitian.

\section{Diskursus Agenda Setting Sebelum Kehadiran Internet}

Agenda Setting berawal dari dua pemikiran yang digagas oleh Walter Lipmann dan Bernard Cohen. Lipmann memandang media massa sebagai pelukis realitas, khalayak tidak dapat dan tidak mungkin mengalami semua peristiwa, walaupun kejadian tersebut membutuhkan respon dari publik (Lipmann, 1965:3-20). Lipmann melihat realitas dicipta oleh media kemudian publik akan menanggapi realitas yang dicipta media. Tidak hanya realitas saja, tapi konstruksi sosial. Sejalan dengan hal tersebut, menurut Long (1992:209) publik yang menanggapi konstruksi realitas yang dicipta oleh media, akan menerima konsekuensi berupa ketergantungan pada media dan distorsi media sendiri, banyak masalah yang timbul dalam kepala kita.

Kemudian Cohen mengungkapkan bahwa "Pers may not successful much of time in telling people what to think, but stunningly successful telling readers what to think about it" (Cohen, 1969:13). Dalam pandangan Cohen, media massa mempengaruhi persepsi khalayak tentang apa yang dipikirkan orang tetapi pers berhasil meyakinkan dan membentuk persepsi publik tentang apa dipikirkan orang tetapi pers berhasil meyakinkan dan membentuk persepsi khalayak.

Kunci dari Agenda Setting adalah penentuan porsi atas suatu isu atau peristiwa dalam proses gatekeeping. Pembentukan persepsi publik dapat diusahakan media dengan memberikan porsi pada setiap masalah atau isu disekitar khalayak, misalnya dengan menonjolkan suatu isu atau peristiwa tertentu dalam sajian media. Perbedaan porsi penyajian tersebut menyiratkan perbedaan atensi, kemudian akan memberikan pengaruh pada kognisi (pengetahuan dan citra) suatu peristiwa atau isu di mata khalayak.

Media massa dalam pendapat Charles Wright (1995:20), melakukan seleksi tentang apa yang disaji pada khalayak dan mengarahkan khalayak bereaksi terhadap suatu isu atau peristiwa yang diberitakan. Media massa menurut Wright memiliki kemampuan mengarahkan isu atau peristiwa untuk diterima khalayak dan diterima sebagai sebuah isu yang penting, atau yang disebut dengan Agenda Setting.

Dalam Agenda Setting, penonjolan isuisu tertentu oleh media massa tidak lepas dari proses seleksi media yang melewati sejumlah pintu (gates), proses seleksi ini bisa dipegang oleh individu atau sekelompok orang yang nantinya akan memutuskan berita layak muat, Mereka inilah yang memainan peran dalam membentuk realitas yang ada di khalayak, gatekeeper media massa biasanya akan menentukan bobot penyajian isu berdasarkan besarnya ruang yang disediakan, penonjolan berita (melalui headline, lokasi penempatan halaman) dan cara isu tersebut dibahas secara detail atau umum (De George, 1981: 219-220). Agenda Setting berangkat dari dua asumsi pokok yakni bahwa media tidak merefleksikan realitas sepenuhnya, dia hanya menyeleksi dan membentuknya. Kemudian penonjolan isu oleh media dalam kurun waktu tertentu akan mempengaruhi publik, dimana publik akan menganggap isu tersebut lebih menonjol daripada isu yang lain (Weaver, $\mathrm{dkk}$, 1981: 3-4).

Roger dan Dearing memperlihatkan bagaimana Agenda Setting ini bekerja. Khalayak bereaksi dan bersikap terhadap sebuah berita merupakan sebuah rangkaian hasil dari media gatekeeping. 
Gambar 1. Agenda Setting

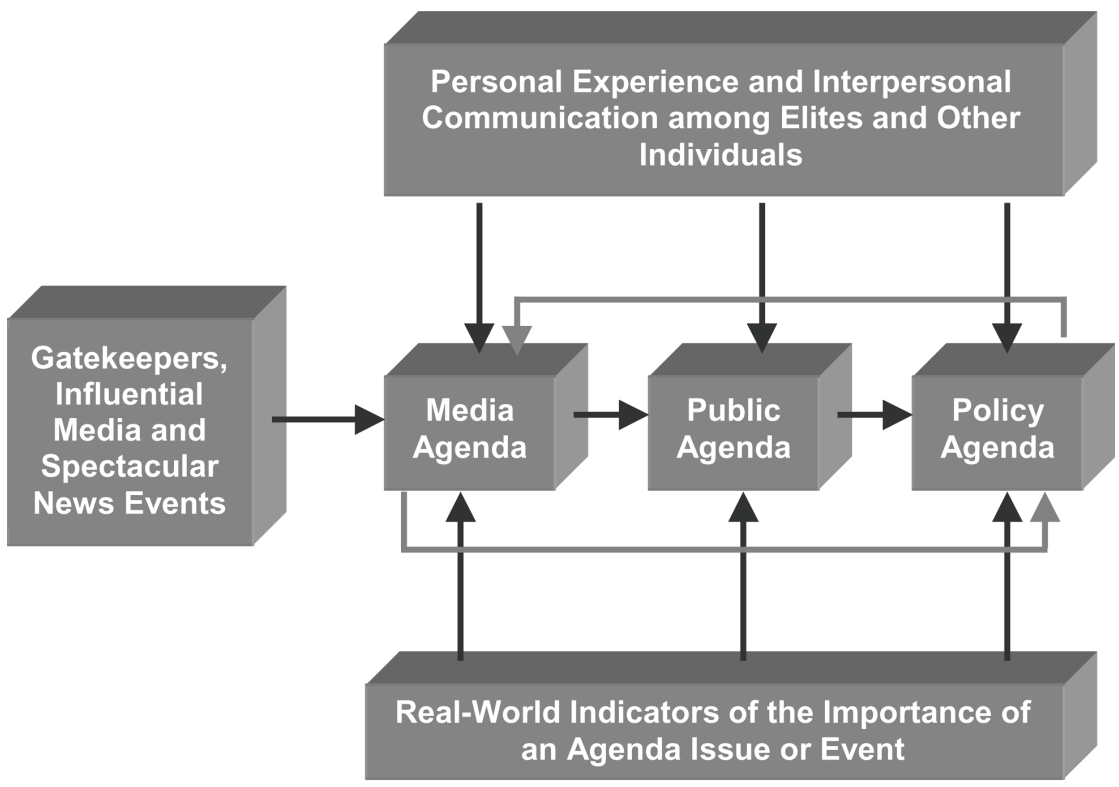

Pada prosesnya, Agenda Setting dapat dibagi menjadi tiga sub area; agenda media, agenda publik dan agenda kebijakan. Agenda Publik merupakan sub area yang mencoba memahami bagaimana opini publik dipengaruhi oleh konten media massa. Sedangkan Agenda Setting media sendiri merupakan studi yang menekankan pada konten media yang berhubungan dengan definisi isu, seleksi dan penekanan yang dilakukan media. Agenda Kebijakan atau Policy Agenda berkaitan dengan relasi antara opini publik pada kebijakan elite, keputusan dan aksi (Rogers dan Dearing,1988:566).

Agenda Media merupakan penentuan isu yang dianggap penting diberitakan dalam media. Biasanya agenda media dituangkan dalam urutan prioritas pemberitaan. Agenda Publik dihasilkan dari proses diskursus dalam publik mengenai isu atau peristiwa di media yang paling penting. Sedangkan agenda kebijakan terbentuk ketika pembuat kebijakan menyadari pentingnya isu tersebut. Ketiga sub area studi tersebut sering digunakan periset untuk menggali seberapa besar kekuatan media dalam mengarahkan suatu isu. Pada perkembangannya, riset lebih banyak dilakukan pada area Agenda Setting Media dan Agenda Setting Publik.

Studi Agenda Setting paling banyak membahas tentang korelasi agenda media dan agenda publik, apakah apa yang dianggap penting oleh media juga dianggap penting oleh publik. Seperti riset yang dilakukan Mc Combs \& Shaw di tahun 1972 memiliki frekuensi paling banyak sebagai rujukan.

Secara metodologis, Selain Mc Combs \& Shaw, Iyegar \& Kinder mengembangkan Contingent Conditions yang mempengaruhi hubungan antara Agenda Media dan Agenda Publik, serta Winter dan Eyal yang mengajukan time lag dalam riset Agenda Setting (Tai,2009:481-513).

Secara garis besar, banyak perkembangan yang terjadi baik secara teoritikal dan metodologikal dalam pengkajian proses Agenda Setting, seperti yang dirangkum dalam berikut : 
Tabel 3

Perkembangan dalam Riset Proses Agenda Setting Sebelum Kehadiran Internet

\begin{tabular}{|c|c|c|}
\hline No & $\begin{array}{c}\text { Inovasi-Inovasi Teoritikal dan Metodologikal } \\
\text { dalam Studi Proses Agenda Setting }\end{array}$ & Penggagas \\
\hline 1 & $\begin{array}{l}\text { Membuat prostulat mengenai hubungan antara } \\
\text { agenda media dan agenda publik }\end{array}$ & Walter Lipmann (1922) \\
\hline 2 & $\begin{array}{l}\text { Mengidentifikasi status-cofferal function dari } \\
\text { media, dimana ada penonjolan yang diberikan pada } \\
\text { isu-isu }\end{array}$ & $\begin{array}{l}\text { Paul F. Lazarfeld dan } \\
\text { Robert K. Merton (1948/1964) }\end{array}$ \\
\hline 3 & Mengawali metafor Agenda Setting & Bernard C.Cohen (1963) \\
\hline 4 & Memberi nama pada proses Agenda Setting & $\begin{array}{l}\text { Maxwell Mc. Combs \& } \\
\text { Donald Shaw (1972) }\end{array}$ \\
\hline 5 & $\begin{array}{l}\text { Menginvestigasi proses agenda setting publik } \\
\text { dengan penyusunan hirarki isu-isu }\end{array}$ & $\begin{array}{l}\text { Maxwell Mc. Combs \& } \\
\text { Donald Shaw (1972) }\end{array}$ \\
\hline 6 & Konsep Framing dan Priming & Tod Gitlin (1980) \\
\hline 7 & $\begin{array}{l}\text { Mengenalkan model proses Agenda Setting- } \\
\text { Kebijakan (policy) }\end{array}$ & $\begin{array}{l}\text { Roger W. Cobb \& } \\
\text { Charles D. Elder (1972/1983) }\end{array}$ \\
\hline 8 & $\begin{array}{l}\text { Mengenalkan studi "over time" dari Agenda } \\
\text { Setting Publik pada analisis level makro dan } \\
\text { menginvestigasikan relasi atau hubungan dari "real } \\
\text { world indicator" ke agenda media }\end{array}$ & G. Ray Funkhouser (1973a) \\
\hline 9 & $\begin{array}{l}\text { Rutinitas Media, ideologi media dan sebagainya } \\
\text { mempengaruhi agenda setting media }\end{array}$ & Shoemaker dan Reese (1981) \\
\hline 10 & $\begin{array}{l}\text { Menginvestigasi secara eksperimental Agenda } \\
\text { Setting-publik pada analisis level mikro }\end{array}$ & $\begin{array}{l}\text { Shanto Iyengar \& } \\
\text { Donald R. Kinder (1987) }\end{array}$ \\
\hline 11 & $\begin{array}{l}\text { Bagaimana sebuah topik terbingkai dan penetapan } \\
\text { unit analisis pada setiap agenda }\end{array}$ & Edelstain (1993) \\
\hline
\end{tabular}

(Sumber : Dearing \& Rogers (1996:9), McCombs \& Shaw (1993:58-67))

Diskursus mengenai teori Agenda Setting pada time lag. Dalam Gandy (1982:7) periode waktu memang menjadi permasalahan dalam penelitian Agenda Setting. Periode waktu ini dikaitkan dengan berapa lamanya sebuah isu atau peristiwa yang disaji media ini bergerak menjadi agenda publik. Untuk beberapa isu atau peristiwa tertentu bisa bergerak dengan mudah ke agenda publik, sedangkan isu atau peristiwa lainnya butuh lebih lama dan dasar teoritikal penelitian Agenda Setting sendiri tidak bisa memprediksi berapa lama senjang waktu (time lag) yang optimal.

Beberapa riset diatas dilakukan sebelum Internet hadir. Kemudian, diskursus muncul mengenai relevansi Agenda Setting jika dikaitkan dengan kemunculan New Media. Teori Agenda Setting merupakan teori komunikasi massa. Untuk Old Media tentu saja Agenda Setting bisa diatur atau bekerja dengan akses terbatas pada informasi, namun bagaimana jika teori tersebut diaplikasikan pada Media Online?

\section{Relevansi Agenda Setting di Era Dunia tanpa Batas}

Pada momen kelahiran Internet, ada sebuah keyakinan media ini akan memberi celah bagi kebebasan berpendapat dengan barriers yang minim. Internet memberikan kesempatan luas dan terciptanya apa yang disebut Kenichi Ohmae sebagai "The Boarderless World"- dunia tanpa batas. Menurut Ohmae batas-batas geografis dan politis negara-negara bangsa tidak relevan dan dibutuhkan lagi (dalam Budiyanto, 1991). 
Teknologi mengubah sistem pengiriman informasi, contohnya Internet, menjadikan pesan didiseminasikan secara instan dan cepat. Sifat Internet yang dinamis, menjadikan media online yang berbasis Internet menyampaikan pesan secara cepat (Roberts, Wanta dan Horng,2002: 453). Selain itu, kanal yang tersedia banyak sehingga jumlah sumber-sumber informasi pun banyak dan beragam. Hal inilah yang menyebabkan sumber-sumber informasi tersedia bagi siapapun yang mencarinya. Inilah yang mengubah respon audiens terhadap media (Bennet dan Iyegar, 2008:2).

Internet sebagai suatu teknologi komunikasi merupakan suatu bentuk media yang berbasis pada perkembangan di bidang komputer. Sebagai suatu media, Internet memiliki beberapa karakteristik yang harus mampu menjalankan mediasi.. Ada dua pandangan mengenai kemungkinan apakah media baru memiliki perbedaan dengan media:

Pertama, media baru Internet memiliki perbedaan dengan media sebelumnya. Terry Flew (2004) menyebut media baru (termasuk Internet) sebagai media konvergen sangat jauh berbeda karakternya dari media sebelumnya. Pertama, Communication Networks, terjadi jaring komunikasi yang mampu merangkai pengakses sehingga terjadi budaya partisipasi. Kedua, Computing/Information Technology, dimana bentuk komunikasi di dalam media ini akan selalu melibatkan teknologi dalam mengolah dan mendistribusikan informasi dengan komputer sebagai perangkatnya. Meski demikian, teknologi menciptakan interaksi sosial yang dinamis di dalamnya. Ketiga, Content. Isi pesan dalam media baru adalah isi pesan lengkap meliputi keseluruhan bentuk pesan media, tertulis, audio, gambar, dan visual. Kemudian Dennis McQuail menyebut perbedaan sangat kentara. New Media sendiri, termasuk media online berbeda dengan media sebelumnya. Dennis McQuail (2010: 141) menyebut ada unsur-unsur yang ada dalam media baru yakni : (1) digitalization and convergence of all aspect media , (2) increased interactivity and network connectivity, (3) mobility and delocation of sending and receiving, (4) Adaptation of publication and audience role, (5) appearance of diverse new forms of media gateway .

Kedua, Media baru Internet masih memiliki kesamaan dengan media sebelumnya. Mengacu pada pernyataan Dennis Mc Quail, fungsi mediasi itu mencakup : Windows, Interpreters, Platform, Interactive Communication, Signpost, Filters, Mirrors, dan Barrier (Littlejohn, 1996:324) maka media baru dan media lama sama-sama memiliki fungsi mediasi. Tetapi media baru (Internet) memperluas fungsi mediasi (remediasi).

Moris dan Ogan (1996:40) melihat bahwa Internet merupakan perluasan dari media-media sebelumnya, dan menyebutnya sebagai "New Mass Medium"-Medium dari suatu komunikasi massa. Mereka mengkritik para ahli ataupun periset uang membatasi model teoritis dalam penelitian serta asumsi dasar dibalik teori mengenai efek media massa, karena itulah para ahli dan periset tidak mampu melihat Internet sebagai media massa yang baru. Artinya, Moris dan Ogan melihat media online ibarat "Old Wine in New Bottle".

Para ahli dan periset yang melihat perbedaan karakter media online dengan media massa sebelumnya tersebut kemudian ragu apakah Agenda Setting masih relevan diterapkan. Interaktivitas yang ditawarkan oleh media online meningkatkan keaktifan para penggunanya. Kemudian, jika consumer media menjadi aktif maka akan mengaburkan garis penghubung media gatekeeper.

Meskipun demikian ada beberapa ahli ataupun periset melihat peluang bahwa Agenda Setting masih relevan diterapkan pada media berbasis Internet. Perubahan teknologi mampu mendiseminasikan pesan secara instan dan aksesnya terbuka sehingga memungkinkan proses komunikasi yang dinamis. Karakter Internet yang dinamis dalam mentransmisikan informasi dari senders (pengirim) ke receiver (penerima), dari titik ini para ahli dan periset berasumsi bahwa teori-teori dari komunikasi massa dapat juga diaplikasikan pada komunikasi online (Robert, Wanta dan Horg, 2002:452).

Landskap media berubah dengan hadirnya media online, menyebabkan 
komunikasi menjadi dinamis dan hal ini menarik para periset untuk melakukan pengujian empirik. Beberapa riset menguji secara empirik teori Agenda Setting sebagai berikut :

1. Scott L Althaus dan David Tweksburry (2002) menguji pada Online Newspaper atau News Portal New York Times dan New York Times versi cetak. Penelitian tersebut memperlihatkan bahwa masingmasing media memiliki efek agenda setting pada masing-masing publiknya, dimana media dan publik memiliki porsi atensi yang sama terhadap isu-isu. Meskipun ada pendapat bahwa dalam media online akan terjadi kekaburan media gatekeeper karena perubahan keaktifan consumer media, namun pada online newspaper tersebut masih terdapat kebijakan editorial. Mereka mengganti cara-cara lama yang berhubungan dengan kebijakan editorial yang mempengaruhi agenda publik. Secara kontras, Online Newspaper menentukan pentingnya isu dengan mengorganisasikan berita berdasar kategori-kategori topikal yang mudah diakses secara cepat pada informasi-informasi yang lebih dibutuhkan dan disukai oleh publik (Althaus dan Tweksburry, 2002:180-207)

2. Yu dan Aikat (2005) menemukan bahwa Agenda Setting masih dapat diaplikasikan pada Internet (media Online). Yu dan Aikat meneliti New York Times dan Washington Post sebagai wakil dari surat kabar online/ Online Newspaper. CNN dan MSNBC untuk TV Online, dan Yahoo News dan Google News sebagai layanan berita online. Mereka melakukan analisis berita selama dua minggu dan menguji korelasi atas publikasi berita-berita tersebut kepada pembacanya, hasilnya terdapat korelasi yang kuat.

3. Coleman dan Mc Combs (2007) menemukan bahwa saat efek Agenda Setting diaplikasikan pada media online pada pengguna Internet yang kebanyakan kaum muda, hasilnya signifikan. Mereka menyimpulkan bahwa penggunaan Internet tidak menghilangkan relevansi teori Agenda Setting.

\section{Kesimpulan}

Fungsi Agenda Setting bekerja pada media online. Pada media online tertentu, misalnya pada online newspaper masih terdapat gatekeeper yang menentukan porsi atensi. Meskipun ada pendapat bahwa dalam media online akan terjadi kekaburan media gatekeeper karena perubahan keaktifan consumer media, namun pada online newspaper tersebut masih terdapat kebijakan editorial. Mereka mengganti cara-cara lama yang berhubungan dengan kebijakan editorial yang mempengaruhi agenda publik.

Kebijakan lama berhubungan dengan cara kerja gatekeeper dalam menentukan prioritas isu dengan penonjolan isu. Dalam Agenda Setting, penonjolan isu-isu tertentu oleh media massa tidak lepas dari proses seleksi media yang melewati sejumlah pintu (gates), proses seleksi ini bisa dipegang oleh individu atau sekelompok orang yang nantinya akan memutuskan berita layak muat, Mereka inilah yang memainan peran dalam membentuk realitas yang ada di khalayak, gatekeeper media massa biasanya akan menentukan bobot penyajian isu berdasarkan besarnya ruang yang disediakan, penonjolan berita (melalui headline, lokasi penempatan halaman) dan cara isu tersebut dibahas secara detail atau umum (De George, 1981: 219-220).

Apa yang diungkapkan de George adalah proses gatekeeping pada media massa. Jika mengacu pada Moris dan Ogan (1996:40) melihat bahwa Internet merupakan perluasan dari media-media sebelumnya, dan menyebutnya sebagai "New Mass Medium"-Medium dari suatu komunikasi massa. Artinya, Moris dan Ogan melihat media online ibarat "Old Wine in New Bottle". Maka meskipun platform media berubah berbasis online, kebijakan editorial beradptasi dengan bentuk tersebut. Penonjolan berita atas sebuah isu bisa dilakukan melalui frekuensi pemberitaan, penyematan headline dalam microsite dan Uploading Time.

Bagaimana dengan consumer yang aktif dan bagaimana gatekeepers mengimbanginya? Secara kontras, media online menentukan pentingnya isu dengan mengorganisasikan berita berdasar kategori-kategori topikal yang mudah 
diakses secara cepat pada informasi-informasi yang lebih dibutuhkan dan disukai oleh publik (Althaus dan Tweksburry, 2002:180-207). Hal ini menunjukkan bahwa Agenda Setting masih relevan di tengah perkembangan media online dan khalayak yang semakin dinamis.

\section{Ucapan Terima Kasih}

Tulisan ini merupakan pengembangan dari penelitian mengenai Agenda Setting oleh penulis Kharisma Nasionalita di tahun 2013 dengan judul "Hubungan Agenda Media Online dengan Agenda Publik Mahasiswa. [Studi Korelasi Agenda Media Online Newspaper kompas.com dengan Agenda Publik Mahasiswa Pascasarjana Fakultas Hukum (FH) Universitas Gadjah Mada (UGM) tentang Isu Korupsi di Indonesia].” Saya berterimakasih atas semua pihak yang turut serta dalam membantu proses penulisan hingga berjalan dengan baik dan lancar

\section{Daftar Pustaka}

Althaus ,Scott L dan Tewksburry, David. 2002. 'Agenda Setting and 'New' News Pattern of Issue Importance among readers of Paper and Online Versions of The New York Times". Communication Research (vol 29), Sage Publication, hal 180-207

Atwater, Tony, Salwon, M.B. dan Anderson, R.B. 1985. "Media Agenda Setting with Environmental Issue”. Journalism Quarterly, Summer, hal 393-397

Bennet, W.Lance dan Iyegar, Shanto. 2008. "New Era Of Minimal Effects? The Changing Foundation of Political Communication". Journal of Communication Forthcoming, hal 2

Berger, Laura J dan Freeman, Michelle D.J. (tanpa tahun). "Relevance of Agenda Setting Theory to Online Community”. Chapman Universty Press, hal 16-34

Brosius, H.Bernd dan M.Kepplinger, 1992. "Beyond Agenda Setting: The Influence of Partisanship and Television reporting on Electoral's Voting Intensions". Journalism Quarterly Vol.69, hal.893-901
Cohen, Bernard C. 1969. The Press and Foreign Policy, 3th ed, New Jersey : Princeton University Press

DeFleur, Melvin L. dan Denis, E. 1981. Understanding Mass Communication, Boston : Houghton Miffin Co

DeGeorge, William F. 1981. "Conceptualization and Measurement of Audience Agenda", dalam Wilhoit, Cleveland dan De Bock, Harold. Mass Communication Review Year Book 2, California : Sage Publication.

Eyal et all.1981. "The Concept of Time Frame in Agenda Setting", dalam Cleveland, Wilhoit dan DeBock. Mass Communication Review Year Book 2. Beverly Hill : Sage Publication.

Gandy, Oscar H. 1982. "Beyond Agenda Setting Research : Where Has It Been, Where is It Going?", dalam Communication Year Book 2, New Brunswick, N.J, Transaction Books.

, Oscar H. 1982. Beyond Agenda Setting Information Subsides and Public Policy. New Jersey : ABLEX Publishing Company.

Hidayat, Dedy N. 1995. Agenda Setting, Bahan Kuliah Metode Penelitian, Jakarta : FISIP Universitas Indonesia.

Kosicki, Gerald M. 1993. "Problem and Opportunities in Agenda Setting Research". Journal of Communication (Vol 43), Hal 43

Lang, Gladys E dan Lang, Kurt. 1981. “Watergate : An Exploration of Agenda Setting”, dalam Withoit, Cleveland \& Debock. Mass Communication Review Year Book 2. Beverly Hill: Sage Publicaton.

Lippman, Walter. 1965, Public Opinion. New York : Mc Millan Publishing Co

Long, Northon dalam Severin, Werner J dan Tackard, James W. Jr. 1992 .Communication Theories : Origins, Method, and Uses in The Mass Media, 3th ed, New York \& London: Longman Publishing Group 
McCombs, Maxwell dan Shaw, Donald L. 1993." The Evolution of Agenda Setting Research: Twenty-Five Years in The Marketplace Idea". Journal of Communication, hal 58-67

, Maxwell dan Shaw, Donald L. 1992., dalam Severin, Werner J dan Tackard, James W. Jr, Communication Theories : Origins, Method, and Uses in Mass Media. Third Edition. New York and London : Longman Publishing Group

, Maxwell. 1981. "The Agenda Setting Approach", dalam Dan Nimmo dan Keit E.Sanders, Handbook of Political Communication, Beverly Hill, London : Sage Publication.

Nasionalita, Kharisma. 2013. Hubungan Agenda Media Online dengan Agenda

Publik Mahasiswa. [Studi Korelasi Agenda Media Online Newspaper kompas.com dengan Agenda Publik Mahasiswa Pascasarjana Fakultas Hukum (FH) Universitas Gadjah Mada (UGM) tentang Isu Korupsi di Indonesia]. Tesis : Universitas Gadjah Mada

Ohmae, Kenichi. The Boarderless World yang telah diterjemahkan dalam Bahasa Indonesia oleh FX Budiyanto.1991. Dunia Tanpa Batas. Jakarta : Binarupa Aksara

Roberts, Marylin, Wanta, W., Horng, T. 2002. "Agenda Setting and Issue Salience Online" . Communication Research (Vol.29), hal 453

Rogers, Everett dan Dearing, JW. 1988. Agenda Setting Research ; Where has it been, where is it going?. Communication Yearbook II. Beverly Hill : Sage Publication.

Rogers, Everett . 1993. "The Anatomy of Agenda Setting”. Journal of Communication eds 43, 1993, hal 68

Tai, Zixue. 2009. "The Structure of Knowledge and Dynamics of Scholarly Communication in Agenda Setting
Research 1996-2005". Journal of Communication. Vol 59, hal 481-513

Warner, J, Severin and Tackard. 1992. Communication Theories : Origins, Method, and Uses in Mass Media. Third Edition. New York and London : Longman Publishing Group

Weaver et all.1981. Media Agenda Setting in Presidential Election, Issue Image and Interest, New York : Praeger Publisher.

Winter, James. 1981. "Contingent Conditions in the Agenda Setting Process", , dalam Withoit, Cleveland \& Debock. Mass Communication Review Year Book 2. Beverly Hill : Sage Publicaton.

Wright, Charles R. 1985. Sosiologi Komunikasi Massa, terjemahan Jalaluddin Rakhmat, Bandung : Remaja Karya

Zucker, Harold G. 1978. "The Variable Nature of News Media Influence" dalam B.D Ruben (eds), Communication Year Book 2, New Brunswick, N.J : Transction Books

\section{Website :}

Vivanews.com

Bahan acuan lain :

Mapping Digital Media : Indonesia 2013, Report by Open Society Foundations 